\title{
Work Experience and Gender Effects on the Work Schedule Preferences of Undergraduate Accounting Students
}

\author{
Sayeedul Islam ${ }^{1}, \mathrm{PhD} \&$ Diane Keyser Wentworth ${ }^{2}, \mathrm{PhD}$ \\ ${ }^{1}$ Farmingdale State College, USA \\ ${ }^{2}$ Fairleigh Dickinson University, USA \\ Correspondence: Sayeedul Islam, Farmingdale State College, USA. E-mail: islams@farmingdale.edu \\ Received: July 15, 2014 \\ Accepted: August 7, 2014 \\ Online Published: August 11, 2014 \\ doi:10.5430/afr.v3n3p127 \\ URL: http://dx.doi.org/10.5430/afr.v3n3p127
}

\begin{abstract}
Previous research has found that one way for accounting firms to attract qualified candidates is by offering non-traditional work schedules. Other research has examined the effects of alternative work schedules with the finding that productivity increases and job satisfaction, commitment, and tenure are higher when schedule alternatives are available to accounting employees. The current study built on this research and assessed the pre and post graduation schedule preferences of 104 undergraduate students enrolled in accounting classes from a private university in the northeastern United States. Results indicated that: 1) those with greater work experience had a lower preference for a standard workweek post-graduation, and 2) females preferred a standard schedule pre-graduation. Explanations for these findings are discussed along with the limitations of the study.
\end{abstract}

Keywords: Work schedules, Recruitment, Accounting, Role conflict

\section{Introduction}

The work schedule difficulties of accountants are not a new phenomenon (Accounting Web, 2008). Work-life balance has been a point of concern for the American Institute of Certified Public Accountants (AICPA) for many years. The 2004 AICPA report discussed the pressing issue of work-life balance amongst accountants. The report indicated that almost $80 \%$ of working accounting professionals were concerned with their work-life effectiveness. This concern for work-life effectiveness has permeated the recruitment materials of the major accounting firms such as KPMG and Deloitte and Touche (Accounting Web, 2008; Greenhouse, 2011). A cursory review of these firms' recruitment websites reveals that each firm attempts to create a message appealing to the concerns of accounting professionals and students with regard to their work-life balance. While the research that has been done on work-life balance amongst accountants has focused on current accountants, the majority of recruitment efforts (via organizational websites) have been geared toward first-time accountants graduating from college. The present research attempts to understand the manner in which accounting students view different work schedule offerings.

The passage of the Sarbanes-Oxley Act of 2002 caused an increased demand across business sectors for high-quality accountants. This law placed greater accounting strictures on corporations in an attempt to increase their accountability. In turn this demand has placed more pressure on individual accounting firms to recruit and hire more accountants (Busta, Becker, Saly, \& Mooney, 2007). The increased workload for accountants has created an increased demand amongst accounting firms for a larger volume of accounting talent. Even though additional accountants are needed, those that are currently working are working harder than ever. As one accountant described it "other professions pay more and don't require 2,800 hours a year" (Dennis, 1997, p. 89). This excess demand leads to a consistently "high rate of turnover in public accounting firms" (Padgett, Paulson, Hughes, Hughes, \& Born, 2005, p. 82). This excess demand continues to this day (Schiavone, 2013).

While it is apparent that current accounting professionals see the value in a healthy work-life balance (Almer \& Kaplan, 2002) this does not take into account the effect of work-life balance on those studying accounting in college. There has been much work done on the effects of work-life balance, work scheduling, etc. on those working in the field of accounting but there has been very little research focused on the work schedule preferences of undergraduate accounting students.

In their study on personality characteristics, values, and goals as antecedents of organizational attractiveness, Rentsch and McEwen (2002) determined that individuals were more attracted to organizations that were similar to 
them than to organizations that were dissimilar to them. The nature of person-organization fit (P-O fit) has been shown as a powerful indicator of organizational attractiveness. Rentsch and McEwen state that "if people are more attracted to organizations with espoused values similar to their own than they are to organizations with goals similar to their own, then recruiters may wish to emphasize P-O value fit in their efforts to attract desirable applicants" (Rentsch \& McEwen, 2002, p. 225). According to the Rentsch and McEwen study, different points of comparison are used by individuals to determine their level of organizational attraction. One of the major findings of this study is "that when it comes to an individual's attraction to an organization it may not matter how the individual and the organization are similar, it matters simply that they are similar" (Rentsch \& McEwen, 2002, p.231).

The effect of person-organization fit has been shown to be a strong indicator of work productivity and work success. Havlovic, Lau and Pinfield (2002) conducted a study on work schedules amongst registered nurses. The nursing industry is in a similar situation to accounting with regards to supply and demand of workers. Nurses also face unique scheduling challenges that are similar to those faced by accountants. Nurses must work in many different shifts and in general are under an increased level of strain during many instances of the work. In turn, there is also an increased demand and growing number of students in the nursing field. Their study showed the power of work schedule congruence. When nurses were working on their preferred schedules and preferred workweeks, they reported a greater level of positive work outcomes and less interference from non-work activities (Havlovic, Lau, \& Pinfield, 2002).

A similar result was found in the pharmaceutical industry. Shepard, Clifton, and Kruse's (1996) study on flexible work hours and productivity indicated that flexible work schedules can increase productivity. This study indicated that the "degree of flexibility was a significant factor influencing productivity" (Shepard, Clifton, \& Kruse, 1996, p.136). Thus it is apparent that not only must scheduling options exist but the type of schedule options that are offered is also important.

However, the question remains, how do these perceived similarities between an applicant and a work environment affect the attractiveness of different organizations to accounting undergraduates? Similarities between an organization and an individual can be described as an association between two different types of values. Organizational culture is defined as "cornerstone values, beliefs, norms, standards, and assumptions concerning work that members of an organization share in common" (Mainiero, 1993, p.64). Thus the work schedules that are offered can be seen as one indicator of organizational culture.

There have also been strong indications in other studies that "presenting work-life benefits to applicants is related to higher perceptions of support during recruitment" (Casper \& Harris 2008, p. 97). These indicators can also serve as unobservable characteristics "even when information about the organization is available from direct observation" (Casper \& Harris, 2008, p. 106). Thus work scheduling can serve as a strong indicator of an organization's unspoken characteristics in the recruitment process. The types of work schedules offered by an organization are a clear indicator of the organization's culture. These options are a clear signal to any potential applicant about the type of culture the organization supports and espouses.

These work schedule options (based on the recruitment material) are the foundation of pre-employment expectations. According to the International Labor Standards website (International Labor Standards, 2013), there are four work schedules that are commonly offered to employees; each consisting of 40 hours per week. The first is the standard workweek that requires an individual to work 8 a.m. -5 p.m. during the traditional (Monday through Friday) workweek. The second is the compressed workweek which requires work during a shorter workweek, usually Monday through Thursday. In the compressed workweek an individual works longer hours each day but fewer days in a week. The third scheduling option is flextime scheduling. Flextime scheduling requires the individual to work certain core hours (usually 10 a.m. to 3 p.m.) but the individual can shift hours earlier or later in the day as needed. The flextime scheduling option also allows an individual to shift some hours to the weekend. The final schedule option is telecommuting which allows an individual to work from home via technology for a predetermined number of days per week.

Pre-employment expectations have been linked to length of tenure in public accounting firms. Pre-employment expectations that do not match the reality of the job can lead to low job satisfaction and low organizational commitment. These are the two most direct antecedents of the decision to leave an accounting firm (Padgett et al., 2005). Some research has indicated that the expectations prior to accepting a job can be more important than the actual experiences an employee has on the job (Padgett et al., 2005). These pre-employment expectations form the foundation of the psychological contract. 
The psychological contract is formed based on two major factors (Rousseau, 1995). The first factor is external messages and social cues sent by the organization. The second factor is an individual's internal interpretations of these messages and the individual's predisposition (Rousseau, 1995). The external messages that an organization sends appear in the form of recruitment materials, etc. These are very clear signals to a potential recruit regarding the organization's culture, its norms, and regulations. In fact in many situations, the only psychological contract that matters to individuals is the contract under which they were hired. These expectations form a promissory note that the organization gives to their employees and form the foundation by which the majority of future events are compared (Rousseau, 1995).

Padgett et al. (2005) focused on these pre-employment expectations. Padgett et al. (2005) drew the conclusion that if employee expectations were met (specifically regarding a flexible schedule), the employees' length of tenure was significantly longer. Thus the effect of the continued completion of the psychological contract was an extension of the employee's tenure. Employees stayed because the pre-employment messaging proved to be true. Overall, the results seemed to indicate that what those in the accounting field wanted most was control over their schedules. This seems to indicate that those with prior accounting work experience would be more likely to desire flexible work scheduling. The culture of accounting will also affect the schedule preferences amongst accounting majors. Accountants understand that their work is seasonal. This understanding is apparent in the culture of accounting and makes those that are studying accounting more apt to partake in some kind of flexible work arrangement. However, the Padgett et al. study (2005) does not draw a clear distinction amongst different types of flexible work schedules.

\section{Hypotheses}

\subsection{Scheduling Preferences Hypotheses}

There has been little research done on the topic of schedule preferences amongst undergraduate accounting students. However, the studies that have been conducted indicate that undergraduate accounting students will show significant differences in preferences between these work schedules. We expect that there will be significant differences in schedule preferences between accounting majors (those whom we presume will work in the field of accounting) and non-accounting majors (those whom we presume will not continue to work in the field of accounting). Specifically non-accounting majors will have a great preference for the standard workweek after graduation.

Hypothesis 1: Non-accounting majors will have a greater preference for the standard workweek after graduation as compared to accounting majors.

\subsection{Role Conflict Hypotheses}

Role conflict is defined as "a situation that results when role expectations are unclear and employees are inconsistent as when a supervisor sends employees mixed messages about their role" (Levy, 2013p. 326). It can be a major factor in work schedule preferences. The level of role conflict can have a major impact on satisfaction, job stressors and burnout. In a study conducted by Almer and Kaplan (2002) in a public accounting firm, flexible work arrangements' effects on such factors as job satisfaction, burnout, and job stressors were analyzed. This study involved a group that worked under a flexible work arrangement and another group that worked under a standard workweek arrangement. The results of this study indicated that "role conflict was significantly lower among professionals under a flexible work arrangement" (Almer \& Kaplan, 2002, p. 30). Professionals working under these conditions also showed a lower level of burnout and emotional exhaustion. Flexible scheduling was also shown to have a significant impact on job satisfaction. This seems to indicate that the more control that an accountant has over his/her own schedule the less likely he/she is to suffer from negative job outcomes. Flexible work schedules are shown to alleviate feelings of emotional exhaustion (Almer \& Kaplan, 2002). This study's most significant result is the clear connection between role conflict and job stressors.

Role conflict is an important factor in the determination and usage of alternative work schedules. Rau and Hyland (2002) focused on an alternative view of flexible work arrangements and applicant attraction. They proposed that applicant attraction to flexible work arrangements was dependent upon the amount of inter-role conflict that an individual felt. Inter-role conflict arises when "pressures arising in one role are incompatible with pressures rising from another role" (Rau \& Hyland, 2002, p. 112). Alternative work arrangements were suggested as a possible solution. Rau and Hyland (2002) focused on the nature of boundaries and their effect on job satisfaction. While alternative work arrangements can offer greater discretion to the individual employee to determine his/her own schedule, they also violated some key boundary rules that each individual has set for him/herself. These boundaries can exist between each individual's different roles (mother, CEO etc.). Rau and Hyland (2002) found that the level of 
attraction to different work arrangements was based on the level of inter-role conflict that the individual faced. Thus someone with a high level of inter-role conflict was more likely to desire flextime scheduling.

Boundary theory can also provide key insights into the undergraduate accounting student population (Desrochers \& Sargent, 2004). Boundary theory states that humans have a need "to create and maintain boundaries that distinguish and order time, space, specific events, or other related constructs into domains that are meaningful for the individual" (Desrochers \& Sargent, 2004, p. 114). However, our understanding of undergraduate accounting students and their boundaries is limited at best. Prior research has indicated that workers with "high levels of all types of role conflict expressed greater attraction to the organization when it was depicted as having a flextime option" (Rau \& Hyland, 2002, p. 129).

Boundary theory also clarifies how important other scheduling options can be to individuals as they navigate the perils of work and home life (Kossek, Lautsch, \& Eaton, 2006). Telecommuting has been shown to "ease transitioning between roles even more than flextime arrangements...psychological and physical gulfs between roles are minimized, temporal boundaries are lessened or nonexistent" (Rau \& Hyland, 2002, p. 117). However, it seems that most students do not have a sense of future role conflict. Phillips and Antoinette's (1998) study of student preferences indicated that "students seem willing to work in jobs that have rigid inflexible work schedules as long as they obtain good jobs."(p. 166) This seems to indicate that students perceive their work life as the overwhelming factor in their post-graduation lives. This may be perceived differently by students in their current situation where their lives are focused on a single role. Thus we hypothesize that flextime and telecommuting will be rated more favorably than standard workweek prior to graduation. We also predict that there will be significant differences in the rankings for standard workweek amongst undergraduate accounting students.

Hypothesis 2: There will be significant differences between the rankings for standard workweek for students enrolled in accounting classes.

Hypothesis 3: Flextime and telecommuting will be viewed more favorably as pre-graduation schedules than standard workweek for students enrolled in accounting classes.

\subsection{Work Schedules and Gender Hypotheses}

One of the major concerns cited in the AICPA report (AICPA, 2004) involves the plight of women in the accounting industry. This is especially apparent in the realm of family-related programs, work scheduling, and other work values (Kleinmann \& Farrelly, 2011). While the report indicates that accounting firms have begun to offer more in terms of flexible scheduling the concerns of women can be seen in the report's results on promotion perception. Gender differences were found in the perceptions of the basis of promotions. Generally, females indicated that they saw a greater role for politics in the promotion process.

This underscores a concern amongst many women with regard to promotions in the accounting industry. While women are happy to have the opportunity to use flexible scheduling or take maternity leave, they are concerned with the effects that this will have on their future career. In Cohen and Single's (2001) study on flexible work arrangements, the perceived negative impact of flexible work arrangements on professional opportunities was analyzed. Their study showed that those employees on a flexible work arrangement "were judged to have a lower likelihood of advancing to partner" (Cohen \& Single, 2002, p. 318).

Perceptions of alternative work arrangements are also a matter of concern for women. These perceptions were studied with regard to performance evaluations, job commitment and career progression judgments in a study conducted by Frank and Lowe (2003). The study indicated that managers seemed to "overlook inadequate performance on current tasks but tend to penalize employees in the long term for being involved in alternative work arrangements" (Frank \& Lowe, 2003, p. 149). The study also indicated that there were no differences between the negative perceptions between men and women. An organization that supports work-life balance in the form of alternative work arrangements can be seen as less likely to hold negative attitudes towards a female's work-family conflict. There is little research to show whether these concerns are in the mindset of female undergraduate accounting students.

Gutek, Searle, and Klepa (1991) offer two major explanations of work-family conflict. The first is the rational role explanation. The rational role explanation states that the more time that is spent in each role, the greater the conflict an individual will perceive between these two roles. The simplest way to describe this rational role explanation is that "there is a main effect relationship between hours and perceived conflict" (Gutek, Searle, \& Klepa, 1991, p. 561). Thus the more hours an employee must commit, the greater the level of perceived conflict. The gender role explanation differs in that if the additional hours are in the traditional gender role domain (i.e. the gender role of 
homemaker for women), then the additional hours feel less burdensome to the individual. If the hours are spent in a non-traditional gender role (i.e. men in the role of housekeeper) then the hours become much more burdensome for the individual. (Gutek, Searle, \& Klepa, 1991). This study showed support for both of these views of work-family conflict. However, in each case, the results showed a stronger relationship for women than for men. In both samples women reported more "work in family" (Gutek, Searle, \& Klepa, 1991, p. 567) conflict despite the fact that they spent the same amount of time at work as men. Thus women have a substantially different experience of work-family conflict than men. A woman's roles can conflict at a greater level and women may be more attracted to a situation where they can control their level of conflict.

Casper and Harris (2008) showed that work-life benefits have a strong effect on an individual's attachment to an organization. Specifically women have been shown to develop strong attachments with organizations based on work-life benefits. A test of two models of attachment (the self-interest utility and signaling) indicated that women used work-life benefits as a way to create a positive impression of the organization. The signaling model states that the availability of a positively perceived policy indicates perceived organizational support and results in long-term organizational attachment. This attachment can affect turnover intentions and work outcomes. The self-interest utility model states that the use of work-life policies by employees creates attachment (Casper \& Harris, 2008). In the signaling model, alternative work arrangements represent the organization's perceived support which leads to organizational attachment. While in the self-interest utility model, if an employee uses the alternative work arrangement, then the employee develops attachment to the organization. Casper \& Harris (2008) showed stronger support for the signaling model. Specifically, they showed that the appearance of work-life benefits increased tenure amongst women regardless of whether the benefits were used or not. Thus work-life benefits in accounting firms can indicate a strong commitment on the part of an organization to the concerns of employees; especially for women.

This research indicates that women are aware of the pressures that they face between the work and family domains. The combination of work and family conflict indicates that women will be more likely to look for flexibility in their scheduling as undergraduates and as working professionals; especially in comparison to men.

Hypothesis 4: There will be significant differences between the pre-graduation and post-graduation ranking of flextime scheduling amongst male and female accounting students.

\section{Method}

\subsection{Survey Participants}

This study was conducted at a private university in the northeastern United States. 122 participants were recruited from undergraduate accounting classes. Of these 122 participants, 18 submitted surveys that were unusable for this study. This resulted in a total of $104(85 \%)$ usable surveys. 53\% (55) of the participants were female and $47 \%$ (48) were male. $50 \%$ (51) of the participants were between $20-21$ years of age, $34 \%$ (35) of the participants were between 18-19 years of age, and 16\% (17) of the sample was 22 years old and over; one participant chose not to answer demographics questions. $47 \%$ (48) of the participants were sophomores, $27 \%$ (28) were juniors and $25 \%$ (26) were seniors.

$50 \%$ (51) of the participants were accounting majors while the other 50\% (51) were non-accounting majors. $97 \%$ (100) of the participants were single and 94\% (97) were without children. $43 \%$ (44) of the participants were not currently working while $36 \%$ (37) worked a flextime schedule, $15 \%(15)$ had a standard workweek schedule, and $6 \%$ (6) worked a compressed workweek schedule. 50\% (52) of the sample had no accounting work experience, while $28 \%$ (29) had less than one year, and 22\% (22) had more than 1 year of work experience.

\subsection{Instrument}

The survey (Appendix A) was created jointly by the authors. It was created to assess current and future work schedule preferences amongst the participants. It was also used to collect standard demographic data of each participant. The instrument was created to be easily understandable by the undergraduate community. The instrument began with a description of the four work schedules. The first work schedule was a standard workweek which was defined as working from 8 a.m. to 5 p.m. and receiving a single lunch break and required no weekends. The second schedule type was labeled a compressed workweek which was described as an individual working from Monday through Thursday from 8 a.m. to 7 p.m.. This schedule did not require work on Friday through Sunday. Flextime was the third work schedule; which was described as work from Monday through Friday with arrival and departure times up to the individual. However, an individual must work from 2 p.m. to 6 p.m. each day and complete 40 hours of work each week. The final schedule type was telecommuting which involved an individual employee working 
Monday through Friday from 8 a.m. to 5 p.m. but choosing to work from home via computer two days a week. All schedules indicated that a total of 40 hours of work was required each week.

These work schedules were described at the beginning of the instrument. The descriptions were meant to serve as reference material for the participants so that they understood the details of each schedule. These descriptions were followed by two tables. The first table was an example with sample rankings where the participants were shown how to rank these work schedules. The next table was blank and was used by the students to rank these schedules. The work schedule that was more preferred was to be ranked \#1, the second most preferred $\# 2$, and the third most preferred \#3, and the least preferred \#4. Each table had two columns, one for participants to rank their current (pre-graduation) schedule preferences and the other to rank their future (post-graduation) schedule preferences.

\subsection{Procedure}

The university's Institutional Review Board reviewed and approved the materials and the administration procedure of the study. Seven separate undergraduate accounting classes were surveyed using the instrument (Appendix A). Participants completed the survey in exchange for in-class extra credit.

\section{Results}

The relationship between the rankings and demographic variables was analyzed using the Mann-Whitney U Test. The effect of work experience was also analyzed using the Mann-Whitney U Test. The Mann-Whitney U Test was chosen for a number of reasons. First, it can be used when the sample size is small. In this study the sample size was small $(n=104)$. The Mann-Whitney was also chosen because it can be used for ordinal data. In this study, the students ranked the different schedule types and thus the Mann-Whitney was deemed most appropriate. The Mann-Whitney test's results indicate mean ranks as a whole. Thus indicating a "lower" score (1 or 2) resulted in a smaller total for the mean ranks and thus a higher ranking in terms of schedule preference.

Hypothesis 1, which stated that non-accounting majors will have a greater preference for the standard workweek in comparison to accounting majors, was not supported. The results in Table 1 indicate that the non-accounting majors do not have a greater preference for the standard workweek post-graduation. There were no significant differences found.

Hypothesis 2, which stated that there would be significant differences amongst the rankings for standard workweek amongst undergraduate accounting students, was weakly supported by the differences in the percentages of rankings found in Table 2. The standard workweek schedule rankings were more evenly distributed post-graduation than pre-graduation. Pre-graduation rankings of the standard workweek indicated a lower preference for the standard workweek amongst undergraduate accounting students.

The results reported in Table 2 are the overall percentages of pre and post graduation rankings. The percentages indicate that flextime is the most highly ranked pre-graduation schedule with $51.9 \%$ of the number one rankings. The lowest ranked pre-graduation schedule was the compressed workweek with $40.4 \%$ of the fourth-place ratings. The two most highly ranked schedules post-graduation were standard workweek and flextime with $28.8 \%$ of the first-place rankings. Compressed workweek was the lowest ranked post-graduation schedule with $32.7 \%$ of the last place rankings. The only schedule that retained the same ranking between pre and post graduation was the compressed workweek which remained in last place. All other schedules received a different percent of aggregate rankings for each schedule type pre and post graduation.

Hypothesis 3 was strongly supported because both flextime and telecommuting schedules were more highly ranked than the standard workweek as a pre-graduation schedule. Flextime was the highest ranking schedule by $51.9 \%$ of the participants while $26 \%$ rated telecommuting as the highest ranking schedule preference pre-graduation. This is in sharp contrast to the $12.5 \%$ first place ranking for the standard workweek. Each alternative schedule is significantly favored in comparison to the standard workweek.

Table 4 examines gender differences on the pre and post graduation schedule preferences. Hypothesis 4 states that there will be significant differences between the pre and post graduation schedule preferences of flextime scheduling amongst male and female accounting students. There were no significant differences found in either the pre or the post-graduation schedules. This indicates no support for Hypothesis 4.

Correlations between each schedule type (standard, flextime, compressed, telecommuting) were found between both the pre and post graduation scenarios using Pearson's $r$. These correlations are summarized in Table 5.All correlations were significant at the .01 level. The strongest correlation $(r=.55)$ between pre and post graduation 
rankings was found for telecommuting. The weakest correlation was found between pre and post graduation rankings for the standard workweek $(r=.30)$. However, all of the correlations were quite significant.

Table 1 displays the results of a comparative analysis done using the academic major (accounting versus other) as the grouping variable. Accounting majors were shown to rank flextime lower as a pre-graduation schedule unlike non-accounting majors who rated flextime higher as a pre-graduation schedule $(U=1035, p<.01)$. Table 3 shows the effects when accounting work experience ( 0 years versus $>0$ years) is used as the grouping variable. The only significant difference found is the relationship between years of work experience and the ratings for standard workweek post-graduation $(U=1081, p<.01)$. These results indicate that the standard workweek was rated lower by those with accounting work experience and higher by those without accounting work experience. Table 4 shows the results of a comparative analysis done using gender as the grouping variable. The only significant effect $(U=1003.5$, $p<.05$ ) in Table 4 was the effect of gender on standard workweek preferences pre-graduation. This result indicates that females rated the standard workweek significantly higher than males as a pre-graduation schedule. This can be seen because the mean rank is much lower amongst the female group $(M=46.25)$ than the male group $(M=58.59)$.

Some differences approached significance such as the effect of major on telecommuting as a pre-graduation schedule preference or the effect of academic major on compressed work week as a post-graduation scheduling preference. This indicates that there might have been a lack of statistical power in this study.

\section{Discussion}

This study has expanded the traditional work scheduling literature by assessing the work schedule preferences of a new population. We analyzed the preferences of accounting students in order to assess the attractiveness of commonly offered work schedules. Similar to the study by Phillips and Antoinette (1998), this study attempted to analyze student preferences. However, unlike Phillips and Antoinette (1998), this study focused on a specific aspect of student preferences, specifically the differences in work scheduling preferences.

Another important aspect of this study is that it has provided the first insight into the schedule preferences of undergraduate accounting students. While many studies (Almer \& Kaplan, 2002; Padgett, et al., 2005) have focused on the work schedule needs of professional accountants, the preferences of students have not been analyzed. This study's results provide important insights into the nature of schedule preferences for not just post-graduation employment but also for pre-graduation student internships. Results indicated that students would be most interested in a flextime schedule.

The hypothesis that undergraduate accounting students would view flextime and telecommuting more favorably than a standard workweek was supported. This is an indication that students desire flexibility in their scheduling. Accounting students, whether they are majoring in the field or majoring in another field, indicated the importance of a flexible scheduling and have made flextime the most preferred pre-graduation and post-graduation schedule type. This result underscores the importance of flexible work arrangements for students. Students perceive their primary role as educational and thus require flexibility to manage their work schedules. Prior to graduation, the individual's role is that of a student and thus any work that exists must fit it itself around the established school schedule. This finding indicates that students perceive their role conflict as students and have chosen a schedule that might match their need to fit their work life around their student life.

The second major finding in this study was that there was little difference between how men and women ranked flextime scheduling pre and post graduation. This does not support the hypothesis that men and women's views on flextime scheduling between pre and post graduation time periods are different. It seems that women are not more aware of potential interrole conflict prior to entering the working world. However, overall flexibility seems to be an important aspect of what these students desire. It would behoove accounting firms to continue to stress the availability of flexible scheduling in their recruitment materials.

A result that remains consistent with much of the work schedule literature was the relationship between years of accounting work experience and the standard workweek as a post-graduation schedule. This result directly supports the work of Almer and Kaplan (2002) who found that flexible work arrangements resulted in lowered stress and burnout. This result indicates that accounting firms should offer fewer standard workweek schedules and should shift towards flexible scheduling.

There were two unexpected results in this study. The first was in the significant differences between men and women with regards to the standard workweek schedule prior to graduation. The result indicated that women preferred the standard workweek more than men as a pre-graduation schedule. This was an unexpected result but seems to hint at a key aspect of female interrole conflict. It appears that even though women are concerned about their future interrole conflict (between work and family life), as undergraduates these work-life balance and interrole concerns do not 
dissuade women from indicating a higher preference for the standard workweek. It may be that women feel that their roles as students and employees are simpler to navigate than the work-family roles. These results also lend support to boundary theory (Desrochers \& Sargent, 2004). In the current study, the standard workweek was the schedule type with the most rigid boundaries. The female preference for standard workweek pre-graduation may indicate that women would prefer that the boundary between student and employee remain intact and clearly delineated.

Another important yet surprising finding involved the relationship between the preferences for a compressed workweek and academic major (accounting versus non-accounting). The results indicate that non-accounting majors rated the compressed workweek much higher as a post-graduation schedule. Presumably accounting majors ranked the compressed workweek lower because these students are more aware of the future pressures that an accountant may face with regard to increased workloads during specific time periods (i.e. the end of the fiscal quarter). The compressed workweek may seem less preferential to accounting majors because the schedule requires too many hours in too short a time period. This result seems to indicate support for accounting majors' fear of overwork. It also indicates some concern on the part of accounting students for what they may have perceived as an inflexible schedule. The compressed workweek as described in this study is much less flexible than either telecommuting or flextime. This result also lends support to the rational role theory (Gutek, Searle \& Klepa, 1991). The compressed workweek offers more time in the work role. Thus because it requires more time, based on the rational role theory, it would not be as highly preferred as other schedule types.

\subsection{Limitations}

The strong pre and post-graduation correlations between flextime, telecommuting, and compressed workweek were also surprising. However, they seem to indicate a limitation within this study. This result appears to support the results of the Phillips and Antoinette (1998) study. Students do not seem to have a clear sense of post-graduation role conflict between their work and home lives. These strong correlations may also have been the result of students' inattention and just completing the surveys very quickly and merely repeating the same rank order regardless of whether they were filling out the pre or post graduation segments of the survey.

These correlations may also be the result of students' inability to envision their future role accurately. Future studies should involve undergraduate students with more accounting work experience. This work experience would better inform their ability to envision their post-graduation work life as accountants and possibly provide more powerful results.

The small sample size also limited this study. There were some instances where the Mann-Whitney U test was close to providing a significant result but did not reach the necessary level of significance. A larger sample size would deliver more statistical power.

Another concern with regard to the sample is with the type of students that were surveyed. The sample consisted of undergraduate students enrolled in accounting classes. Little distinction was made based on academic major. Future studies should focus primarily on accounting majors. This would allow for stronger generalizability to the larger population of future accountants. If a student is merely studying undergraduate accounting because he/she is a business, marketing, etc. major, then their views on these schedules would be distinctly different than those majoring in accounting.

\subsection{Conclusions and Future Research}

While the results of this study have limitations, it does provide a foundation for understanding undergraduate accounting students' scheduling needs. This study provides the first glimpse into the mindset of the accounting student and lays the foundation for understanding how scheduling reflects their work experience. Future studies should delve deeper into understanding the process by which undergraduate students make their recruiting decisions vis-à-vis work schedule preferences. The focus must be on putting work schedule preferences in the larger context of organizational attractiveness.

Future research must also focus on the role of gender on schedule preferences. The results of this study indicate a different attitude amongst men and women than previously assumed. Role conflict is another important area where this study's results may be further explored. The nature of student role conflict as they choose an internship or a major has yet to be studied. This area might provide intriguing insights into the differences between the accounting student and accounting professional.

The role of the psychological contract amongst undergraduate accounting students should be explored as well. The effect of the implied promises made to undergraduate accounting students was merely hinted at it in this study. Future research should focus on the nature of the psychological contract on student workers. 
The demand for accountants will continue to increase for the foreseeable future, as will the increase in the workload of individual accountants. In this demanding atmosphere, understanding the effects of scheduling is extremely important. However, for firms to be competitive in the recruitment market, their understanding of accounting students' preferences must increase. Understanding the differences between students and professionals can only help to illuminate our understanding of the recruitment process.

Table 1. Schedule Rankings Pre and Post Graduation: Effect of Major

\begin{tabular}{|c|c|c|c|c|}
\hline Schedule Type & Name Group & $N$ & Mean Rank ${ }^{\mathrm{a}}$ & $p$-value \\
\hline \multirow[t]{3}{*}{$\overline{\text { Standard Pre-Grad }}$} & Accounting & 51 & 52.39 & \multirow{3}{*}{.75} \\
\hline & & & & \\
\hline & Other & 51 & 50.61 & \\
\hline \multirow[t]{2}{*}{ Standard Post-Grad } & Accounting & 51 & 52.74 & \multirow[b]{2}{*}{.66} \\
\hline & Other & 51 & 5026 & \\
\hline \multirow{3}{*}{ Compressed Pre-Grad } & Accounting & 51 & 50.06 & \multirow{3}{*}{.60} \\
\hline & & & & \\
\hline & Other & 51 & 52.94 & \\
\hline \multirow[t]{2}{*}{ Compressed Post-Grad } & Accounting & 51 & 56.59 & \multirow[b]{2}{*}{.07} \\
\hline & Other & 51 & 4641 & \\
\hline \multirow{3}{*}{ Flextime Pre-Grad } & Accounting & 51 & 56.71 & \multirow{3}{*}{$.05^{*}$} \\
\hline & & & & \\
\hline & Other & 51 & 46.29 & \\
\hline \multirow[t]{2}{*}{ Flextime Post-Grad } & Accounting & 51 & 47.69 & \multirow[b]{2}{*}{.18} \\
\hline & Other & 51 & 55.31 & \\
\hline \multirow{3}{*}{ Telecommute Pre-Grad } & Accounting & 51 & 46.33 & \multirow{3}{*}{.07} \\
\hline & & & & \\
\hline & Other & 51 & 56.67 & \\
\hline \multirow[t]{2}{*}{ Telecommute Post-Grad } & Accounting & 51 & 48.86 & \multirow[b]{2}{*}{.35} \\
\hline & Other & 51 & 54.14 & \\
\hline
\end{tabular}

${ }^{a}$ Mean ranks calculated using the Mann Whitney U Test

*Statistically significant at $p<.05$

Table 2. Ranking Percentages Pre and Post Graduation*

\begin{tabular}{|c|c|c|c|c|c|c|c|c|}
\hline \multicolumn{9}{|c|}{ Schedules } \\
\hline \multirow[b]{2}{*}{ Rank } & \multicolumn{2}{|c|}{ Standard } & \multicolumn{2}{|l|}{ Compressed } & \multicolumn{2}{|c|}{ Flextime } & \multicolumn{2}{|c|}{ Telecom. } \\
\hline & Pre & Post & Pre & Post & Pre & Post & Pre & Post \\
\hline 1 & $12.5 \%$ & $28.8 \%$ & $9.6 \%$ & $18.3 \%$ & $51.9 \%$ & $28.8 \%$ & $26 \%$ & $24 \%$ \\
\hline 2 & $18.3 \%$ & $21.2 \%$ & $19.2 \%$ & $26 \%$ & $26 \%$ & $31.7 \%$ & $36.5 \%$ & $20.2 \%$ \\
\hline 3 & $41.3 \%$ & $27.9 \%$ & $30.8 \%$ & $23.1 \%$ & $10.6 \%$ & $22.1 \%$ & $17.3 \%$ & $27.9 \%$ \\
\hline 4 & $27.9 \%$ & $22.1 \%$ & $40.4 \%$ & $32.7 \%$ & $11.5 \%$ & $17.3 \%$ & $20.2 \%$ & $27.9 \%$ \\
\hline
\end{tabular}

*Percentage of participants indicating the rank of each work schedule with rank $1=$ most desirable, $2=$ second most desirable, 3 = third most desirable, $4=$ least desirable 
Table 3. Schedule Rankings Current and Future: Effect by Amount of Accounting Work Experience

\begin{tabular}{|c|c|c|c|c|}
\hline Schedule Type & Name Group & $N$ & Mean Rank ${ }^{\mathrm{a}}$ & $p$-value \\
\hline \multirow[t]{2}{*}{ Standard Pre-Grad } & 0 years of experience & 52 & 47.29 & \multirow[b]{2}{*}{.09} \\
\hline & $>0$ years of experience & 51 & 56.80 & \\
\hline \multirow[t]{2}{*}{ Standard Post-Grad } & 0 years of experience & 52 & 46.28 & \multirow[b]{2}{*}{$.04 *$} \\
\hline & $>0$ vears of exnerience & 51 & $5783+2>30$ & \\
\hline \multirow{3}{*}{ Compressed Pre-Grad } & 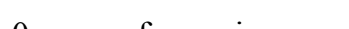 & 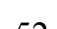 & -5600 & \multirow{3}{*}{.13} \\
\hline & & & & \\
\hline & $>0$ years of experience & 51 & 47.72 & \\
\hline \multirow[t]{3}{*}{ Compressed Post-Grad } & 0 years of experience & 52 & 54.09 & \multirow{3}{*}{.46} \\
\hline & & & & \\
\hline & $>0$ years of experience & 51 & 49.87 & \\
\hline \multirow[t]{2}{*}{ Flextime Pre-Grad } & 0 years of experience & 52 & 52.71 & \multirow[b]{2}{*}{.80} \\
\hline & $>0$ years of experience & 51 & 51.27 & \\
\hline \multirow[t]{2}{*}{ Flextime Post-Grad } & 0 years of experience & 52 & 56.73 & \multirow{2}{*}{.09} \\
\hline & $>0$ years of experience & 51 & 47.18 & \\
\hline \multirow[t]{2}{*}{ Telecommute Pre-Grad } & 0 years of experience & 52 & 52.41 & \multirow[b]{2}{*}{.88} \\
\hline & $>0$ years of exnerience & 51 & 5158 & \\
\hline \multirow[t]{2}{*}{ Telecommute Post-Grad } & 0 years of experience & 52 & 50.70 & \multirow[b]{2}{*}{.65} \\
\hline & $>0$ years of experience & 51 & 53.32 & \\
\hline
\end{tabular}

${ }^{a}$ Mean ranks calculated using the Mann Whitney U Test

*Statistically significant at $p<.05$ 
Table 4. Schedule Rankings Pre and Post Graduation Effect by Gender

\begin{tabular}{|c|c|c|c|c|}
\hline Schedule Type & Name Group & $N$ & Mean Rank ${ }^{\mathrm{a}}$ & $p$-value \\
\hline \multirow[t]{2}{*}{ Standard Pre-Grad } & Female & 55 & 46.25 & \multirow{2}{*}{$.03 *$} \\
\hline & Male & 48 & 58.59 & \\
\hline \multirow[t]{3}{*}{ Standard Post-Grad } & Female & 55 & 50.13 & \multirow{3}{*}{.48} \\
\hline & & & & \\
\hline & Male & 48 & 54.15 & \\
\hline \multirow[t]{2}{*}{ Compressed Pre-Grad } & Female & 55 & 55.11 & \multirow{2}{*}{.23} \\
\hline & Male & 48 & 48.44 & \\
\hline \multirow{3}{*}{ Compressed Post-Grad } & Female & 55 & 52.59 & \multirow{3}{*}{.23} \\
\hline & & & & \\
\hline & Male & 48 & 51.32 & \\
\hline \multirow[t]{2}{*}{ Flextime Pre-Grad } & Female & 55 & 52.63 & \multirow{2}{*}{.80} \\
\hline & Male & 48 & 51.28 & \\
\hline \multirow[t]{2}{*}{ Flextime Post-Grad } & Female & 55 & 53.96 & \multirow[b]{2}{*}{.46} \\
\hline & Male & 48 & 4975 & \\
\hline \multirow[t]{3}{*}{ Telecommute Pre-Grad } & Female & 55 & 53.96 & \multirow{3}{*}{.46} \\
\hline & & 10 & 1075 & \\
\hline & Male & 48 & 49.12 & \\
\hline \multirow[t]{2}{*}{ Telecommute Post-Grad } & Female & 55 & 51.90 & \multirow[b]{2}{*}{.97} \\
\hline & Mol & 10 & 521 & \\
\hline
\end{tabular}

${ }^{a}$ Mean ranks calculated using the Mann Whitney U Test

*Statistically significant at $p<.05$

Table 5. Correlations for Work Schedule Types

\begin{tabular}{|c|c|c|c|c|}
\hline Work Schedule Type & Std. Post-Grad & Flex Post-Grad & Tele. Post-Grad & Comp. Post-Grad \\
\hline Std. Pre-Grad & $.30 *$ & - & - & - \\
\hline Flex Pre-Grad & - & $41^{*}$ & - & - \\
\hline Tele. Pre-Grad & - & - & $.55^{*}$ & - \\
\hline Comp. Pre-Grad & - & - & - & $.51 *$ \\
\hline
\end{tabular}

${ }^{*}$ Correlation is significant at the .01 level (2-tailed) 


\section{References}

Accounting Web. (2008). KPMG survey of accounting students discloses what studentslook for in jobs. Retrieved from

http://www.accountingweb.com/topic/education-careers/kpmg-survey-accounting-students-discloses-what-stude nts-look-jobs

Almer, E. D., \& Kaplan, S. E. (2002). The effects of flexible work arrangements on stressors, burnout, and behavioral outcomes in public accounting. Behavioral Research in Accounting, 14, 1-34. http://dx.doi.org/10.2308/bria.2002.14.1.1

American Institute of Certified Public Accountants. (2004). AICPA Work/Life and women's initiatives 2004 research. New York: AICPA.

Busta, B., Becker, D., Saly, J. P., Sathe, R. S., \& Mooney, K. (2007). Effective campus recruiting: The faculty perspective. The CPA Journal, 77(7), 62-65.

Casper, W.J. \& Harris, C.M. (2008). Work-life benefits and organizational attachment: Self-interest utility and signaling theory models. Journal of Vocational Behavior, 72, 95-109. http://dx.doi.org/10.1016/j.jvb.2007.10.015

Cohen, J.R. \& Single, L.E. (2001). An examination of the perceived impact of flexible work arrangements on professional opportunities in public accounting. Journal of Business Ethics, 32(4), 317-318. http://dx.doi.org/10.2308/bria.2002.14.1.1

Dennis, Anita (1997). Profiting from scheduling alternatives. Journal of Accountancy, 184(5), 87-93.

Desrochers, S. \& Sargent, L.D. (2004). Boundary/border theory and work-family integration. Organization Management Journal, 1(1), 40-48. http://dx.doi.org/10.1057/omj.2004.11

Frank, K. E., \& Lowe, J. (2003). An examination of alternative work arrangements in private accounting practice. Accounting Horizons, 17(2), 139-151. http://dx.doi.org/10.2308/acch.2003.17.2.139

Greenhouse, S. (2011, January 7). Flextime flourishes in accounting industry. The New York Times. Retrieved from http://www.nytimes.com/2011/01/08/business/08perks.html?pagewanted=all\&_r=0

Gutek, B.A., Searle, S., Klepa, L. (1991). Rational versus gender role explanations for work-family conflict. Journal of Applied Psychology, 76, 560-568. http://dx.doi.org/10.1037/0021-9010.76.4.560

Havlovic, S. J., Lau, D.C., \& Pinfield, L. T. (2002). Repercussions of work schedule congruence among full-time, part-time, and contingent nurses. Health Care Management Review, 27(4) 30-41. http://dx.doi.org/10.1097/00004010-200210000-00004

International Labor Standards (2013). United States: Working Time. Retrieved from http://www.ilo.org/gateway/faces/home/polareas/worktime?locale=en\&countryCode=USA\&track=STAT\&poli cyId $=6 \& \_$adf.ctrl-state $=705 \mathrm{yh} 6 \mathrm{r} 5 \mathrm{j} \_80$

Kleinmann, G.B. \& Farrelly, G.E. (2011).The work values of accounting students. The Journal of Applied Business Research, 15(1), 59-68.

Kossek, E.E., Lautsch, B.A., \& Eaton, S.C., (2006). Telecommuting, control, and boundary management: Correlates of policy use and practice, job control and work-family effectiveness. Journal of Vocational Behavior, 68(2), 347-367. http://dx.doi.org/10.1016/j.jvb.2005.07.002

Levy, P. E. (2013). Industrial Organizational Psychology: Understanding the Workplace New York, NY: Worth Publishers.

Mainiero, L. A. (1993). Is your corporate culture costing you? Academy of Management Executive, 7(4), 84-85. http://dx.doi.org/10.5465/AME.1993.9503103244

Padgett, M., Paulson, K., Hughes, G., Hughes, S. B., \& Born, C. J. (2005). The relationship between pre-employment expectations, experiences, and length of stay in public accounting. Journal of Leadership and Organizational Studies, 12(1), 82-102. http://dx.doi.org/10.1177/107179190501200108

Phillips, C.R., \& Antoinette, S. (1998). The tables turned: Factors MBA students use in deciding amongst prospective employers. Journal of Employment Counseling, 35, 162-168. http://dx.doi.org/10.1002/j.2161-1920.1998.tb00998.x 
Rau, B. L. \& Hyland, M. M. (2002). Role conflict and flexible work arrangements: The effects on applicant attraction. Personnel Psychology, 55(1), 111-136. http://dx.doi.org/10.1111/j.1744-6570.2002.tb00105.x

Rentsch, J.R. \& McEwen, A. H. (2002). Comparing personality characteristics, values, and goals as antecedents of organizational attractiveness. International Journal of Selection and Assessment, 10(3), 225-234. http://dx.doi.org/10.1111/1468-2389.00212

Rousseau, D. M. (1995). Psychological Contracts in Organizations: Understanding Written and Unwritten Agreements $\left(1^{\text {st }}\right.$ ed.). Thousand Oaks, CA: Sage Publications.

Schiavonne, J. (2013). AICPA report finds record hiring for accounting grads. Retrieved from http://blog.aicpa.org/2013/07/aicpa-report-finds-record-hiring-for-accounting-grads.html\#sthash.1N1MICNF.dp bs

Shephard, E. M., Clifton, T. J., \& Kruse, D. (1996). Flexible work hours and productivity: Some evidence from the

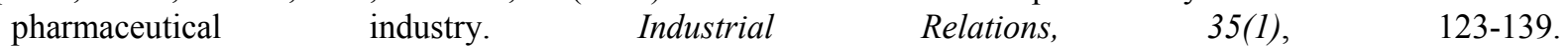
http://dx.doi.org/10.1111/j.1468-232X.1996.tb00398.x

Appendix A

\section{FLEXIBLE SCHEDULING}

The following page describes four different work schedules and asks your preference for each. There are no right or wrong answers. The last page contains some general questions about you. DO NOT PUT YOUR NAME OR ANY OTHER IDENTIFYING INFORMATION ON THIS PACKET OF INFORMATION.

Your responses will only be reported as part of a group, no individual responses will be reported. If your instructor is giving credit for completing this project he/she will maintain a separate list of names for that purpose.

THANK YOU FOR YOUR PARTICIPATION!!! 


\section{Scheduling Options}

Please read the following descriptions of work schedules. On the next page you will be asked to rate these scheduling options from a scale of 1 (most preferred) to 4 (least preferred). You will be asked to rate these schedules based on your personal preference now and your perception of what you think it will be after your graduate.

For each type of schedule listed below, the employee would be working the exact same number of hours (40 hours per week)

\section{Standard workweek}

Your schedule is Monday through Friday from 8:00AM-5:00PM. You would receive a one-hour lunch break and not be expected to come in for weekends unless otherwise needed.

\section{Compressed workweek}

Your schedule is Monday through Thursday from 8:00AM-7:00PM. You would receive a one-hour lunch break and would not be expected to come in to work from Friday to Sunday unless otherwise needed.

\section{Flextime}

Your schedule is Monday through Friday. You can choose when to arrive or leave work at your discretion as long as you are in the office between the hours of 2:00PM-6:00PM as part of your work hours and work a total of 40 hours each week. You can also choose to shift some of your hours to the weekend.

\section{Telecommuting}

Your schedule is Monday through Friday from 8:00AM-5:00PM. However, you have the option of working from home and telecommuting two days a week. 
Use the descriptions from the previous page to rate each type of work schedule. Rank each schedule type from $1=$ most preferred to $4=$ =least preferred. An example is provided below. Be sure to rank all of the work schedules twice, once according to what schedule you would like to be working NOW and once according to what schedule you think you will prefer AFTER YOU GRADUATE.

\begin{tabular}{|l|l|l|}
\hline \multicolumn{2}{|l|}{ EXAMPLE } & $\begin{array}{l}\text { Your preference } \\
\text { NOW }\end{array}$ \\
\hline Schedule Type & $\begin{array}{l}\text { Your preference } \\
\text { AFTER YOU GRADUATE }\end{array}$ \\
\hline Standard workweek & & \\
\hline Compressed workweek & & \\
\hline Flextime & & \\
\hline Telecommuting & & \\
\hline
\end{tabular}

\section{$1=$ Most preferred $\quad 4=$ least preferred}

\begin{tabular}{|c|c|c|}
\hline YOUR RANKIN & & \\
\hline Schedule Type & $\begin{array}{l}\text { Your preference } \\
\text { NOW }\end{array}$ & $\begin{array}{l}\text { Your preference } \\
\text { AFTER YOU GRADUATE }\end{array}$ \\
\hline 1. Standard workv & & \\
\hline 2. Compressed wc & & \\
\hline 3. Flextime & & \\
\hline 4. Telecommuting & & \\
\hline
\end{tabular}


Demographics

Please check one response for each question

5) Gender: Female

12) What is your major?

Male

6) Age Range: 18-19

Accounting

20-21

22-24

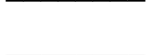

25 and above

7) Marital Status: Single, never married

$\begin{array}{ll}\text { Married } & \\ \text { Divorced } & \\ \text { Widowed } & \end{array}$

8) Do you have children?

Yes

No

9) Total number of years of accounting work experience (including internships)

None

Less than 1 year

1-2 years

3-5 years

Over 5 years

10) Your current status at FDU based on your number of completed credits

Freshman

Sophomore

Junior

Senior

Graduate Student

11) What is your current type of work schedule (using the definitions from page 1)?

Not working currently

Standard workweek

Compressed workweek

Flextime

Telecommuting

THANKS FOR YOUR PARTICIPATION IN THIS STUDY! 